\title{
The influence of slope factor for the construction of sandy shoal in the lakeshore zone
}

\author{
Qianru Wang ${ }^{1, \text { a }}$, Yuanfu Zhang ${ }^{1, ~ b,{ }^{*}}$, Chenlin $\mathrm{Hu}^{1, \mathrm{c}}$, \\ Chaowei Jiao ${ }^{1, d}$,Jingling Wang ${ }^{1, e}$, Xiaoyu $\mathrm{Du}^{1, \mathrm{f}}$ \\ ${ }^{1}$ School of Energy Resources ,China University of Geosciences (Beijing), Beijing100083, China \\ a15501260710@163.com, bzhang.yuanfu@163.com, ${ }^{\mathrm{c}} 343730428 @ q q . c o m$

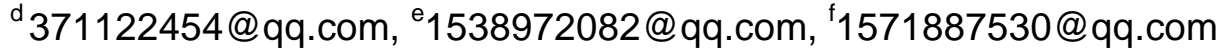

${ }^{*}$ Corresponding author

Keywords: sandy shore, shoal, slope, flume simulation.

Abstract. In order to clear and define the influence of slope factor for the construction of sandy shoal, the research presents developmental process of sandy shoal through flume simulation from the perspective of sedimentology forward modeling. The experiment is divided into three groups by using the method of control variable in the can wave flume device. The condition such as waves, source remains unchanged, and changing slope of every group, the tangent of three slopes is respectively $1 / 15 、 1 / 20 、 1 / 25$. The experimental results show that the developmental degree of sandy shoal in the lakeshore zone is better, the thickness is larger as the slope increases; the scale of the bar is smaller as the slope decreases, because the waves cannot hit the bottom shape. The marginal slope value where the scale of the bar changes obviously is $1 / 20$. The research this time studies the influence of slope factor for the construction of sandy shoal in the lakeshore zone from the angle of sedimentology through quantitative flume simulation experiment, providing a reference for the further research of shoal.

\section{Introduction}

Sedimentology simulation experiment is an important experimental method and technical means to study the depositional process of sediments. Among the production practice, what we deal with is almost sedimentary rocks after a long geological period and preserved. The explanation of all kinds of sand body formation process is almost the idea of inversion, Lots of information which reflects the process of deposition has been lost. Therefore, for the study of sedimentary processes, it is primarily through modern sedimentary investigation and laboratory sedimentary simulation (Junhui Wang et al. , 2013; Min Li et al. , 2013). Sandy shoal in the lakeshore zone is very common in nature, many geologists have carried out detailed theoretical studies for the sandy shoal in nature (Zhili Zou et al. , 2009; Zaixing Jiang et al. , 2015), they have also noticed that slope has an influence on the construction of sandy shoal in the lakeshore zone through their simulation studies. However, the question that how slope controls specifically the construction of sandy shoal is not studied thoroughly. The reason is that the laboratory simulation of wave exists a certain difficulty and they do not control variable for the slope in the process of simulating sandy shoal and so on.

The study aims at problems above about waves as well as control variable, with new wave maker, and it explores the construction of sandy shoal through laboratory flume simulation. The experiment uses the method of control variables, in order to study the influence of slope for the construction of sandy shoal in the lakeshore zone, so the study is able to provide a basis for the study of the slope factor of sandy shoal, and offers a reference for the further research of shoal. 


\section{The experimental device}

The simulation experiment of sandy shoal is carried out in a new deposit simulation flume module, simulating the environment of small lake basin, the concrete flume device of this experiment is shown in Fig. 1.

The main body of lake basin is composed of retractable stainless steel flume. The length is 4 meters, and the width is 1.5 meters, meanwhile the height of it is 0.2 meters, establishing a three-dimensional coordinate system for data acquisition. A1, A2, A3 in Fig. 1 are sand device, having nothing to do with the experiment. B is a sedimentary area, and this experiment observes experimental phenomena and results here, $\mathrm{C}$ is a water recycling system, moreover $\mathrm{D}$ is a storage system, and $\mathrm{E}$ is a bracket system. The length of the flume is retractable, the experiment uses the length of the flume which is 2.63 meters. This experiment changes the gradient through liftable and lowerable slope, the length of slope is 1.5 meters, and its width is 1.4 meters. At the same time, the experiment simulates waves using the wave maker (Fig. 1, c), in order to realize stable wave parameters, and simulate the environment of lake basin better.
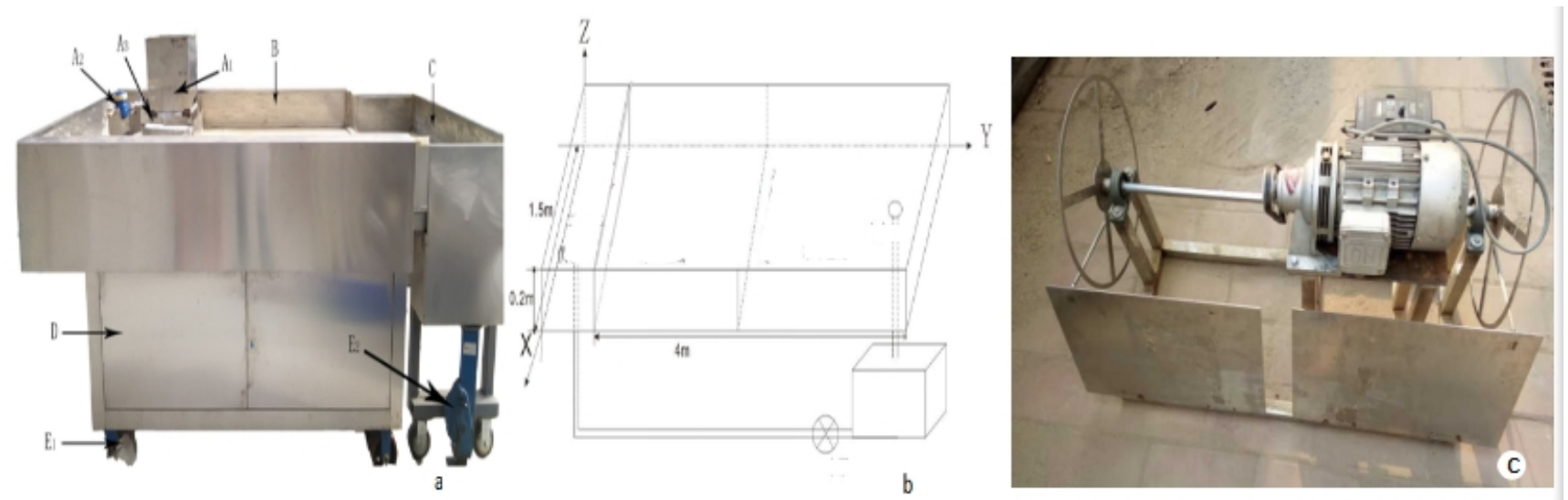

Fig. 1. The experiment facility (a), its sketch (b) and the wave maker (c)

\section{The experimental process}

This experiment is divided into three rounds (RUN1 RUN2 RUN3), parameters such as wave, source supply, sand composition, time and or so remain unchanged in three experiments, except that slope value changes. Experiments simulate the sandy shoal in the lakeshore zone formed in different slopes. The slope of three rounds of experiments increases in turn, the flume builds sandy shoals in the lakeshore zone for the same wave conditions. And we observe experimental phenomena after an hour, then we measure and record the thickness of foreshore and backshore everywhere (Table 1).

Table 1 The experiment parameter table

\begin{tabular}{|c|c|c|c|c|c|c|c|c|c|}
\hline $\begin{array}{l}\text { the } \\
\text { experimental } \\
\text { round }\end{array}$ & $\begin{array}{c}\text { slope } \\
\text { (tangent) }\end{array}$ & $\begin{array}{l}\text { initial } \\
\text { sand } \\
\text { thickness } \\
(\mathrm{cm})\end{array}$ & $\begin{array}{l}\text { time } \\
(\mathrm{min})\end{array}$ & $\begin{array}{l}\text { lake } \\
\text { level } \\
(\mathrm{cm})\end{array}$ & $\begin{array}{l}\text { sand } \\
\text { composition } \\
\text { (gritsilt clay) }\end{array}$ & $\begin{array}{l}\text { the lowest } \\
\text { thickness in } \\
\text { foreshore } \\
\text { (cm) }\end{array}$ & $\begin{array}{l}\text { the highest } \\
\text { thickness in } \\
\text { backshore } \\
\text { (cm) }\end{array}$ & $\begin{array}{l}\text { the average } \\
\text { thickness in } \\
\text { foreshore } \\
(\mathrm{cm})\end{array}$ & $\begin{array}{l}\text { the average } \\
\text { thickness in } \\
\text { backshore } \\
\text { (cm) }\end{array}$ \\
\hline RUN1 & $1 / 25$ & 2 & 60 & 10 & $2: 3: 1$ & 2.00 & 3.20 & 2.50 & 2.90 \\
\hline RUN2 & $1 / 20$ & 2 & 60 & 11 & $2: 3: 1$ & 2.00 & 4.00 & 2.00 & 3.93 \\
\hline RUN2 & $1 / 15$ & 2 & 60 & 14 & $2: 3: 1$ & 2.70 & 4.60 & 2.82 & 4.23 \\
\hline
\end{tabular}

\section{The description of phenomena}

\section{The description of planar shape}

The phenomena before and after three rounds of experiments are shown in Fig. 2, ab, cd, ef are respectively the results of RUN1, RUN2, RUN3. The planar shape of sandy shoal shows a long strip 
which is parallel to the shoreline. From the experimental phenomena, we can observe that the scale of sandy shoal built in the lakeshore zone is larger when slopes get more. The scale of sandy shoal is smaller when slope decreases. Meanwhile, by analyzing the experimental data we can also quantitatively draw conclusions above. When the slope is $1 / 25$, the difference between the lowest thickness in foreshore and the highest thickness in backshore is smaller, which is 1.20 centimeters; When the slope is $1 / 15$, the difference of thickness is larger, which is 1.90 centimeters; while the corresponding difference of thickness is 2.00 centimeters when the slope is $1 / 20$, which is almost the same as the difference of RUN3. Thus we can learn that $1 / 20$ is the theoretical value where the rate of change about scale is the largest. Then by comparing the average thickness in backshore we can draw a conclusion that the thickness of sandy shoal in the lakeshore zone increases with slope increasing.

The research has also carried out several tests in addition to three rounds of formal experiments. In other trials, when in a certain slope $(\tan \alpha=1 / 20)$, parameters of wave maker is 13 , water depth is 15 centimeters, and initial sand thickness is 3 centimeters, we could observe the underwater beach bar of a good development in front of the foreshore of sandy shoal after 60 minutes' experiment. It is the good reservoir in shore and shallow lake zone. At the top of the beach bar, its middle shows fine grained, and its both sides shows coarse grains. The beach bar manifests a long strip in parallel with the shoreline(Fig. 3) .

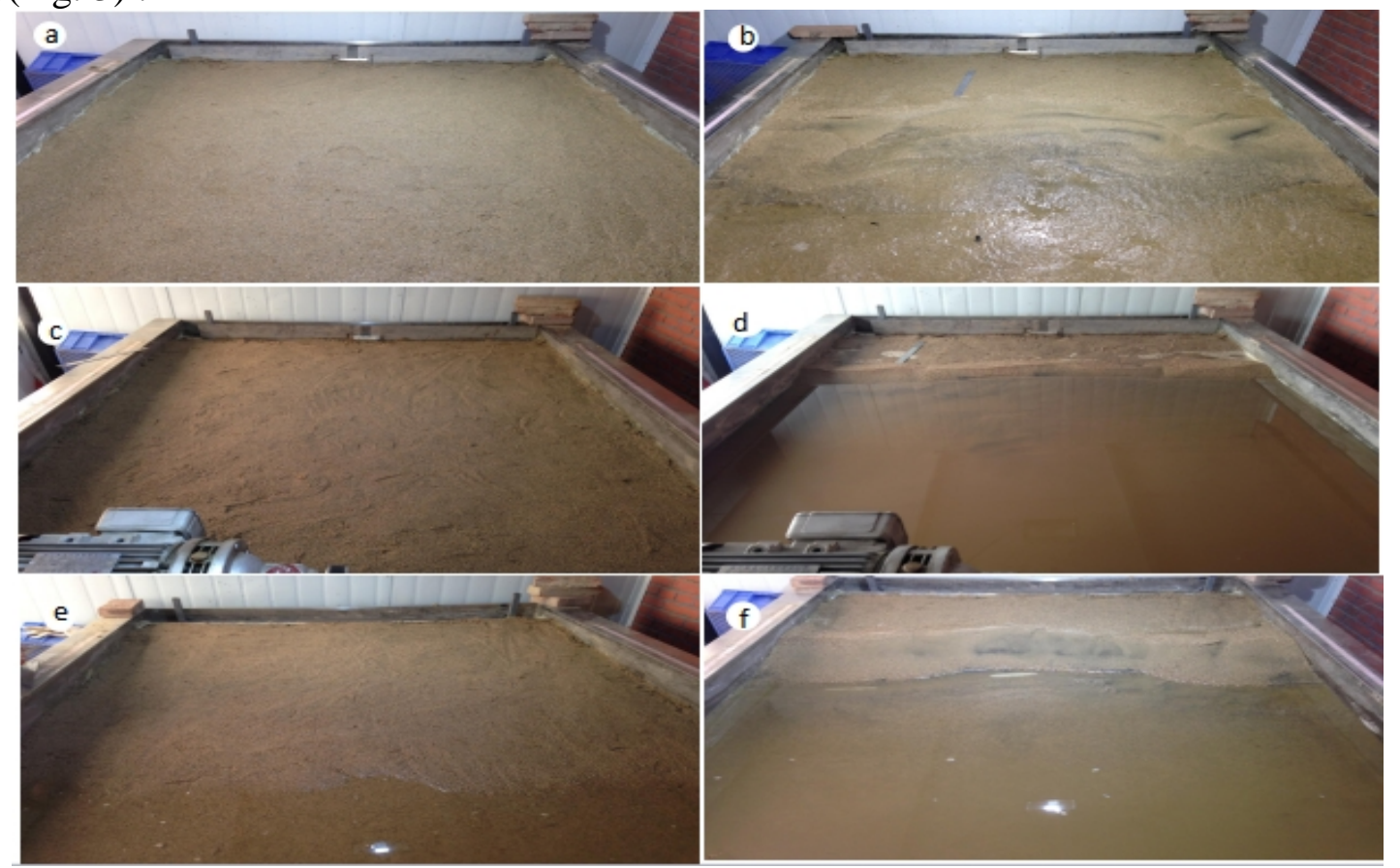

Fig. 2. The comparative planar graph before and after three groups of experiments

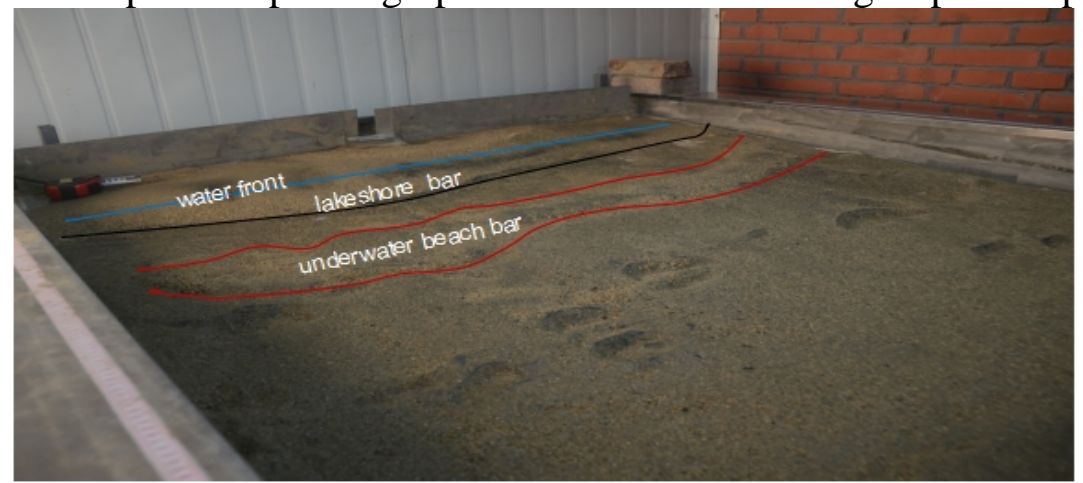

Fig. 3. The planar of underwater beach bar

\section{The description of profile bedding}

The thickness in backshore of sandy shoal in the lakeshore zone is larger after experiments, and the thickness in foreshore is thinner. The profile of sandy shoal shows reverse graded bedding(Fig. 4, a b), 
cutting section vertically for sandy shoal in the lakeshore zone, we can observe the phenomenon that particles at the bottom of the sand body are finer and granularity gradually coarsens upwards.

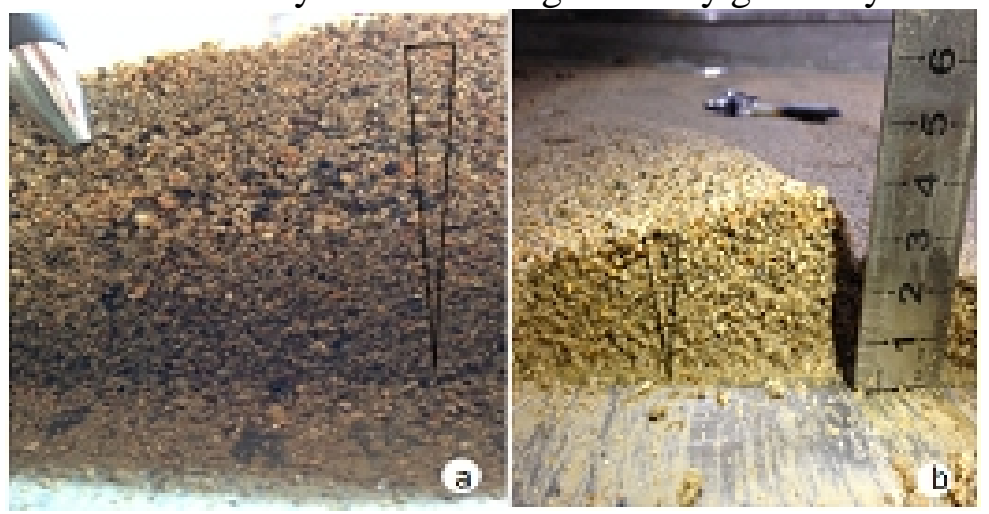

Fig. 4.The profiles of sandy shoals

\section{The explanation of mechanism}

In surfing backflow zone, water depth is shallow, and the middle of lake transmits pulse currents onshore. Because the asymmetry of wave velocity becomes more and more obvious closer to the shore, the movement velocity of water body onshore is more and more fast, and the pulse current is stronger. Under the action of gravity, the waves will form an underflow offshore on the bottom of the lake, the farther underflow is to the shoreline, the weaker intensity is. When underflow offshore and "pulse currents" onshore reach a balance, it can cause the accumulation of clastic substance near the shoreline, forming the sandy shoal studied. The formation of sandy shoal is the result of the elutriation of waves back and forth, the backshore is developed at the side of the coastline onshore, and the foreshore is developed at another side of the coastline offshore( Zaixing Jiang,2010). The formed sandy shoal has two forms onshore or offshore in a certain time, but in the end it can stay in a stable position, its movement direction is related to the initial slope(Yang Zhang et al,2015) .

When the slope is higher, the thickness and scale of sandy shoal formed in the lakeshore zone are bigger. Its mechanism is that the high gradient leads to a high slope and full source supply, the waves of shallow water occur to break when meeting the shore, tip-over water body scours lakebed intensively and stir up a lot of sediments, forming the distribution of sand body; however, when the slope is smaller, source supply is poor, the waves can not hit the bottom shape, and the sand body is not disturbed, so the development thickness is thinner. Thus we can get the regularity that slope is proportional to the developmental thickness of sandy shoal in the lakeshore zone.

The separation of sandy shoals observed by experimental results is very good, and maturity of shoals is high. The profile shows reverse graded bedding. The generation of this phenomenon results from that the energy of water body gradually decreases from the lake level to the lakebed. So particle-size carried by water changes from coarse to fine, there are plasma depositing in the lakebed, and coarse grains depositing near the lake surface. Thus the overall performance is reverse graded bedding. As the elutriation of waves goes, the reverse graded phenomenon is more obvious.

\section{Conclusions}

On condition that wave, lake level, source, sand composition, and time remain unchanged, with the increase of topographic slope( within less than 10 degrees), the developmental thickness of sandy shoal in the lakeshore zone goes up, and the scale gradually enlarges, sand body scale of the slope tangent value which is $1 / 20$ (the difference between the lowest thickness in foreshore and the highest thickness in backshore) changes obviously. 
The formation of sandy shoal in the lakeshore zone is the result of underflow offshore and "pulse currents"onshore work together, because waves scour and the water body energy decreases from the lake level to the lakebed, its textural maturity is very high, and it has reverse graded bedding.

When the slope is higher, the reason that the thickness of sandy shoal is bigger is that the waves hit the bottom shape of sand body, which provides the source for the formation of sand body, and leads to the thickening of sand body. On the contrary, the sandy shoal is thinner because the waves don't stir up sand body.

\section{Acknowledgements}

This work was financially supported by the National Natural Science foundation of China (No.41572092), College students' innovative experiment projects (class A) (201511415035), National Major Projects (No.2011ZX05009-002), and Opening Project of Key Laboratory of Marine Reservoir Evolution and Hydrocarbon Accumulation Mechanism, Ministry of Education.

\section{References}

[1] Junhui Wang, Zaixing Jiang and Yuanfu Zhang: Oil and Gas Geology. (2013), 34(6): 758-764. (In Chinese) .

[2] Min Lin, Hongtao Zhu and Qiaozhen Guo: Geo-logical Science and Technology Information. (2010), 29(4): 137-141. (In Chinese) .

[3] Yang Zhang, Zhili Zou and Daxun Gou: Haiyang Xuebao. (2015), 37(1): 147-157. (In Chinese) .

[4] Zaixing Jiang, Sedimentology, Petroleum Industry Press, Beijing, (2010): 153-163. (In Chinese) .

[5] Zaixing Jiang, Junhui Wang and Yuanfu Zhang: Journal of Palaeogeography. (2015), 17(4): 427-440. (In Chinese) .

[6] Zhili Zou, Coastal Hydrodynamics, China Communications Press, Beijing, (2009): 4-17. (In Chinese) . 